\title{
What is a Theory-Practice Gap? An exploration of the concept
}

\author{
Kathleen Greenway, Graham Butt \& Helen Walthall
}

\section{Abstract}

In nursing literature, the phrase 'theory-practice gap' is widely used without common definition or description of its underlying concept. This review paper presents a concept analysis using Rodgers (2000) evolutionary process to define and clarify the concept of the theory-practice gap as part of a doctoral study. In so doing it provides a deeper understanding of the concept to enable its consistent application within nurse education. A theoretical definition is developed, the data search that was undertaken is described and a discussion of the attributes, antecedents and consequences is provided. We conclude by offering, a model case, which is employed to illustrate the concept.

\section{$\underline{\text { Introduction }}$}

The primary aim of this doctoral research programme using case study methodology, was to explore the existence of a theory-practice gap, using student nurses' experiences of administering intramuscular injections (IMI) within their clinical placements as the case. The administration of IMIs forms part of the essential skills clusters for pre-registration nurses (NMC 2010) and is one of many skills performed by registered nurses, that may appear to an onlooker to be an easy skill to execute, yet the practice appears to be fraught with inconsistencies. The practice to administer an IMI by registered nurses is not evidence based, which results in a variety of techniques being used without fully rationalise their practice (Walsh and Brophy 2010). This scenario can leave students unsure of which method they should use as often what they are taught in university is not being reflected by their mentors in clinical practice. This results in a theory-practice gap. 
The phrase theory-practice gap is commonly used in nursing literature, often without consistent definition or description, with the gap regularly referred to as being 'bridged', 'breached', 'avoided' or 'negotiated'. A persistent theorypractice gap is evident in nursing literature (Rolfe, 2002, Maben et al 2006, Monaghan, 2015) and frequently mentioned in contemporary research, yet there is little clarity about its virtual or real characteristics; hence there are omissions and confusion in our common understanding of this phenomenon. As a consequence of this lack of consensus a conceptual analysis of the term was deemed necessary. Walker and Avant (2005) suggest several reasons for completing a concept analysis, ranging from developing operational definitions, to clarifying the meaning of an existing concept, to adding to existing theory. The process for undertaking a concept analysis has been linked with philosophical inquiry, which in turn uses intellectual analysis to clarify meaning; moreover in this instance it was crucial as Duncan et al (2007) argue to embody a shared meaning within a professional discipline to enable effective communication.

\section{Background}

Scully (2011) indicates that despite the differing interpretations of the nature of the theory-practice gap, there is widespread agreement that it represents the separation of the practical dimension of nursing from that of theoretical knowledge (Rolfe 1998, 2002). During the process of completing this concept analysis it was possible, in the absence of any other given definition, to create and emergent definition of the theory-practice gap as:

'The gap between the theoretical knowledge and the practical application of nursing, most often expressed as a negative entity, with adverse consequences.'

A definition is important as the theory-practice gap is not tangible; it represents a metaphorical void which is felt or experienced, yet is not easily measurable or quantifiable. Consequently, analysis of the components of the theory-practice gap was expected to produce a classification, a 
standardisation of the concept, and an adoption of the common meaning and relevance to nursing and nurse education.

The theory-practice gap has persisted in nursing and continues to have negative connotations, although its continued presence may facilitate dynamic change within the profession (Haigh 2008), highlighting the separation between theoretical or evidence-based knowledge and practical elements of nursing (Scully 2011). This gap between theory (what should happen), and what occurs (what actually happens) in the clinical environment is not new. Yet it is not only the practical skills of new graduate nurses that are questioned (Voldbjerg et al 2016), it is also the potential lack of proficiency among nurses in both their clinical skills and critical thinking abilities. Thus the theory-practice gap remains a continuing problem for nursing, felt both by experienced and newly qualified and student nurses (Scully 2011). Despite the more frequently articulated negative associations of the theory-practice gap, the concept is not always regarded as being resolutely negative. Ousey has coherently argued, in a debate with Gallagher (Ousey and Gallagher 2007), that the presence of the theory-practice gap can encourage students and staff to question and thus to avoid complacency in their practice. Monaghan (2015) suggests as the theory-practice gap begins during preregistration education, effecting clinical skills capabilities of student nurses, collaboration between universities and practice is essential for the development of the nursing profession.

\section{Method:}

Risjord (2009), provides a comprehensive critique of the epistemological foundations of concept analysis and deems that it can be seen as an arbitrary and vacuous exercise when it is performed in an unsupported and unjustified fashion. A concept analysis therefore needs to be undertaken using a theoretical framework, essential for providing operational definitions.

Traditionally a concept analysis within nursing has used Wilson's (1963) method, although many authors have subsequently modified and adapted 
Wilson's framework. Currently, the two most used frameworks within nursing are those of Walker and Avant (2005) and Rodgers (2000). Walker and Avants' framework omits the issue of contextualisation which is central within Rodgers' (2000) evolutionary framework. Rodgers' framework emphasises the dynamic way concepts and theories change over time, or considers when different contexts are reviewed at the same point in time; thus when the context of use alters, so must the meaning, focussing on the current application of the concept and its interconnectedness with other factors. The theory-practice gap might not only exist in nursing (it might also exist in other professions such as medicine or teaching, for example) thus the contextual features and application of Rodgers model, together with its emphasis on temporal and heuristic elements, was reasoned to provide the most appropriate framework for this conceptual analysis. The presentation of this concept analysis will follow the steps as described below in Rodgers' model.

\section{Steps in Rodgers' (2000) model}

Rodgers (2000) advocates no preconceived descriptions of a concept should be allowed; instead stating a concept must come from searching the literature using a systematic technique. Although Rodgers' model has evolved from Wilson's (1963) original 11-step model, it has been refined into an 8-step process as shown in table 1:

\section{Rodgers' Evolutionary Model}

- 1. Identify the concept of interest

- 2. Identify surrogate terms

- 3. Choose the setting and the sample

- 4. Identify the attributes

- 5. Identify the references, antecedents and consequences

- 6. Identify related concepts

- 7. Identify a model case

- 8. Identify implications for further research and development of the concept 


\section{Concept of interest}

Within nursing there is perceived to be a gap between theory and practice which is persistent and mostly has negative connotations; yet whilst there is the awareness that it can be felt or experienced, it is not easily measured or quantifiable. Therefore the theory-practice gap required describing, defining and exploring; in achieving this it becomes valid for the advancement of the understanding of the concept within nursing, in both education and practice (Duncan et al 2007).

\section{Surrogate terms}

Rodgers (2000) refers to surrogate terms as being similar or related; those that can be identified as synonymous to the term theory-practice gap. This was difficult to quantify as the only other synonym identified was the 'education-practice gap' - succinct terms to encompass the void or gulf between theory and practice were not found. Substitute words such as 'schism', 'gulf' or 'dichotomy', instead of gap, were infrequently used. However these did not offer a complete, surrogate term, rather they were merely descriptive, alternative semantics.

\section{Choosing the setting and sample}

The keywords for the literature search were derived from the term 'theorypractice gap' and its surrogate term 'education-practice gap' using the CINAHL, BNI, BEI and MEDLINE databases. Limits for English language, for peer reviewed journals and with a publication date ranging from 2005-2016 were applied. The results were as indicated in Figure 1 


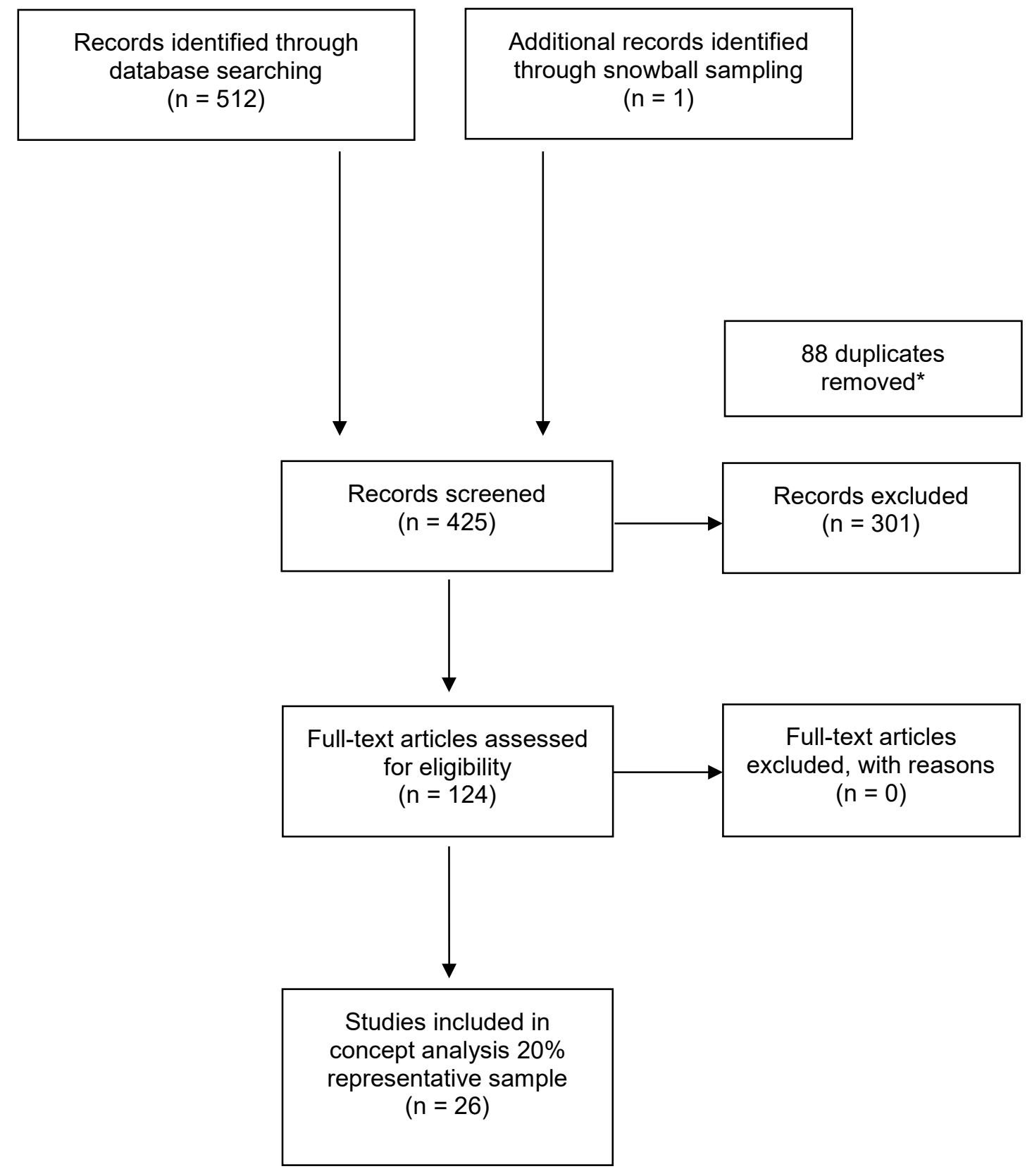

* 88 papers were identified as being duplicates on multiple databases and an excel spreadsheet was created to list and compare the occurrences of each paper within the databases searched. 
Figure 1 - PRISMA style diagram representing the audit trail of the search strategy using the Rogerian process.

After removal of the duplicates, and the preliminary screening of the abstracts, a total of 124 papers remained for detailed screening. The papers excluded by this process mostly referred to 'bridging' or 'overcoming' the theorypractice gap, without recourse to defining the term or providing any insight into the nature of the concept. In accordance with Rodgers' process of sampling, $20 \%$ of the total results $(n=26)$ were retrieved commencing with a random starting point to select the literature for inclusion in the analysis. This was then used as the representative sample to complete the concept analysis. Whilst the majority of the papers retrieved were research studies, using Rogerian sampling it is also accepted practice to include any other cognitive conception of the concept under scrutiny. As concepts are cognitive conceptions, Tofthagen and Fagerstrøm (2010) concur that data sources can include professional literature, interviews, or other forms of verbalised language; several papers which included debates, expressions of personal experiences or editorial opinions were therefore included in this concept analysis, though these represent the minority.

\section{$\underline{\text { Results }}$}

A diagram to clarify the findings of the concept analysis is represented in figure 2 below:

-Evidence-based practice

- Ritualistic practice -Education \& acquisition of nursing skills

\section{Antecedents}

\section{Attributes}

-Relational problems between university and clinical practice

-Practice fails to reflect theory

- Theory perceived as irrelevant to practice

\section{Consequences}

-Influence on nurses and nursing students

-Disparity in collaboration between university and clinical practice 
Figure 2 diagrammatic representation of the concept analysis of the theorypractice gap

\section{Attributes of the theory-practice gap}

Rodgers (2000) refers to attributes as elements that constitute the core or real definition of any concept, which may be totally at odds with a straightforward dictionary definition as meaning may alter as a consequence of context. The seminal paper by Allmark (1995) was included as the additional paper sourced in the search strategy, despite it being outside the search timeframe criteria, (see figure 1), as it was repeatedly cited within the retrieved papers. Its value as a foundational paper was therefore duly noted. Allmark's paper provided a framework for how the theory-practice gap presented itself in different ways which, after reviewing the literature, could be seen as the 'attributes' (with minimal revisions from Allmark's original paper).

The attributes of the theory-practice gap are identified as:

- Relational problems between university and clinical practice

- Practice failing to reflect theory

- Theory perceived as irrelevant to practice

\section{$\underline{\text { Relational problems between university and clinical practice }}$}

Debate between Gallagher and his co-author Ousey (Ousey and Gallagher 2007), identifies how nursing in the UK, Australia, New Zealand, USA and Canada has over a short space of time, created a physical separation between theory and practice. This is essentially a consequence of moving from an apprenticeship model based in hospitals, to a university/college based model of nurse education. In Monaghan's (2015) critical literature review, gaps between two segregated units of theory and clinical practice in the students' learning present challenges regarding how to incorporate the 
two aspects of nursing. Although this separation was undertaken to elevate nursing to a graduate profession, the outcome has been a lack of integration between university and clinical staff in planning the students' clinical education. The role of the Lecturer-Practitioner (LP) was created in the 1990s in the UK with the specific aim of bridging the theory-practice gap. Hancock et al (2007), in an evaluation study, explored the experiences of LPs and found that as well as supporting students in practice and providing academic teaching, their role included the development of clinical skills for newly qualified nurses. Their joint appointment promoted their clinical credibility and encouraged stronger links between practice and education. However, Barrett (2007), in his critical review, states limitations of the LP role resulting in split loyalties, heavy workloads, unclear career structures and limited effectiveness of the post holder.

The introduction of joint clinical chairs in nursing, whereby a professorial position is created as a collaborative appointment between a university and the healthcare provider, has also been heralded as another means of bridging the theory-practice gap. Such strategic and operational posts, specifically designed to straddle the realms of academia and clinical practice, appear ideally placed to cultivate research and develop clinical practice. Nonetheless, Darbyshire's (2010) critical editorial, laments how constant capricious change within the organisations regarding focus and priorities, fosters the impossibility of filling these positions - a problem further compounded by a lack of suitable applicants. This is particularly unfortunate given that Evans (2009), in his review of mental health nurse training, argues that mutual collaboration requires a top down leadership approach supporting the two institutions in developing a joint strategy for student learning.

Hence the roles of LPs and joint chairs were created with the aim of increasing collaboration between the parties, as well as targeting, influencing and cascading issues for research or practice. It is apparent that the full potential of these roles may not yet have been reached. 


\section{Practice failing to reflect theory}

Haigh (2008) suggests that academics often imply clinical areas are unwilling or unable to change practice or adopt new ideas, but if we are to mature and gain credibility as a profession we need to respond to change as a direct result of theoretical or exploratory research in the clinical area. This is a position supported by Glenn (2006) who contends that a solution may lie in translational research, whereby findings from significant research projects are identified and applied at the patient/service user level. Nonetheless, clinicians may be aware of the new research in their area of specialty, yet interpret it in a different manner to academics. Haigh (2008) suggests that clinicians may actively choose to adjust or adapt research to serve their needs, or those of their patients. Whilst this is a constructive way of considering why research is not effectively incorporated, a time lag often exists when applying evidence to practice.

The positive motivation to promote change and to reduce the theory-practice gap, is achieved in part by professional socialisation and effective role modelling, but when these are lacking, motivation is lost. Maben et al (2006), in a longitudinal study, noted how newly qualified nurses arrive on wards with a consistently high set of ideals and values that were largely thwarted in practice. This happens as a consequence of 'organisational sabotage', whereby factors such as staff shortages, poor skill mix, workload, time pressures, high patient turnover and role constraints lead to an inability of nurses to care for patients as they want to, and as they have been taught. Student participants also reported what amounted to 'professional sabotage', including feeling unsupported and often having poor role models, which left them (and newly qualified nurses) unable to make sense of the gaps they encountered.

\section{Theory perceived as irrelevant to practice}


Rolfe (2002) argues there is a correlation between out-dated theories, linked with the misconception of the relationship of theory to practice. However, other authors (Maben et al 2006, Ousey and Gallagher 2007) suggest the fault lies with the lack of socialisation of the theories into the clinical setting and the failure to integrate research into the clinical practice environment. Haigh (2008) suggests this aspect of the theory-practice gap should be embraced, not despised. The dynamic and evolving nature of nursing implies old theories will become irrelevant whilst new theories and skills being developed, will require testing and evaluation. When new skills or theories are accepted, or well evaluated, there is a need to cascade into the global nursing network. It is therefore inevitable that a gap is experienced until such time as the transfer of knowledge or skills is complete.

Additionally, as nurse education is split between clinical practice and the university, there is a need to prioritise applying theory in context specific and workable ways. The use of human patient simulators (HPS) within a simulated based education (SBE) to provide a more realistic yet controlled classroom environment has been advocated as a way of making skills learning more representative of the contextual realities of everyday clinical practice. The claim university lecturers are out of touch with reality, not clinically credible and that the theories they espouse do not reflect practice, opposes the previous position. Ousey and Gallagher (2010) refute this statement in their debate regarding the clinical credibility of nurse educators. They argue maintaining such credibility is not of paramount importance, stating that this is an unrealistic expectation of lecturers given their pressure of work and requirement to display competence so to remain on the professional register. Ousey and Gallagher (2010) find this debate to be an unnecessary distraction, arguing that emphasis should be on partnership between academia and clinical practice, whilst the issue of clinical credibility should instead be focused on the mentor in practice. Myall et al (2008) have declared effective mentorship to be pivotal to students' clinical learning experiences; this is of particular importance as mentors provide the summative assessment of a student's clinical practice. Therefore, the need for a competent, clinically credible, research aware and reflective mentor is extremely desirable. Indeed, 
this is increasingly regarded as essential for the effective professional socialisation of nursing students and to assist them in reducing the theorypractice gap.

\section{$\underline{\text { References }}$}

Rodgers (2000) describes references as the contexts or situations in which the concept might occur, rather than the way the term is used within academia. Whilst the theory-practice gap is found with poorly socialised students and newly qualified staff when practising in the clinical environment (Scully 2011, Monaghan 2015), it does remain a concern for all staff. Maben et al (2006) therefore describe it as having a persuasive and enduring nature in professional practice. The phenomenon is not unique to nursing and is correspondingly described in the literature for other professions worldwide, including medical students (Smeby and Vagan 2008, Sanfilippo 2015) and student teachers (Cheng et al 2010, Korthagen et al 2006, Allen 2009). The premise of how the theory-practice gap presents for these professions is similar, and the experiences of it for students, mentors and educationists appears to be comparable.

\section{$\underline{\text { Antecedents }}$}

Rodgers (2000) defined an antecedent as a situation that must occur prior to the concept happening and which cannot be considered as a defining attribute; in essence these factors are the causes of the phenomenon occurring. Antecedents for the THEORY-PRACTICE gap are evidence based-practice, ritualistic practice, and the education and acquisition of nursing skills.

\section{Evidence-Based Practice}

Traditionally the term theory, as applied to nurse education, was synonymous with theoretical education (Ousey and Gallagher 2007) as well as to academic discourse and publications, although now use of both the terms 'theory' and 
'evidence' is considered necessary to underpin nursing decisions and nursing care. These terms, whilst separate, should form part of the same connotation when discussing the theory-practice gap, and evidence should be assumed to be part of 'theory'.

The use of Evidence-Based Practice (EBP) within nursing is an approach to providing care, which integrates nursing experience and decision-making alongside valid, credible and current research (Aveyard and Sharp 2017). It is founded upon the premise that standards are developed according to patient outcomes rather than procedures. The onus of decision making has moved from the practitioner to the patient in a partnership arrangement with tacit intuitive knowledge being recognised, but it does not drive the entire decision making process. Registered nurses are also bound by their Code of Professional Conduct, the NMC (2015) in the UK, which states nurses should always practice in line with the best available evidence. The interpretation of this clause is that nurses must seek the best available evidence to review, applying it to their practice whilst keeping their patient fully informed. The clause also implies fostering respect for the patients' input into the decisions made.

Thus EBP has the capacity to form foundations of theory, or to alter standing theories. As such, it forms an antecedent to the theory-practice gap and consequently nurses need to constantly revisit practice in light of the latest evidence and to make action plans of how change can be managed, directed and supported by individuals, organisations and teams.

\section{$\underline{\text { Ritualistic practice }}$}

Ritualistic practice is a routinised behaviour, which does not require knowledge or understanding often performed without consideration of clinical need. It is the continuation of ritualised practices, rather than applying and embracing EBP, that leads to a lack of change meaning practice remains in a static state. However, rituals are not always negative actions, as some nursing rituals are necessary or have positive outcomes, such as the nursing 
shift handover (Scovell 2010) where an accepted formulaic process ensures effective communication and handover of care.

Ousey and Gallagher (2007) have recognised how student nurses contend with ritualistic practice, in that it does not replicate what they have been taught in university. They suggest whilst students are encouraged to question, they should also be aware that resource implications (such as skill mix issues, or staff shortages) may mean they cannot practice exactly as they have been taught. Students therefore face a conundrum: of accepting that the reality of practice does not reflect an ideal theoretical basis, or of questioning the clinical practice they see. Although students know to question practices, they are also aware their mentor will be assessing their clinical practice and that nursing operates in a hierarchical structure. As such students may feel powerless or unwilling to contest decisions made.

\section{The education and acquisition of nursing skills}

A nursing curriculum requires consolidation of knowledge and its grounding in professional practice. With regard to recent changes in the provision of skills education, the introduction of simulation based education (SBE), within a clinical skills laboratory (CSL), was seen as a potential means of reducing the theory-practice gap. In the UK, the use of simulation was actively promoted following the NMC's Simulation and Practice Learning project (2007) whereby findings confirmed that the use of simulation should be actively encouraged within the pre-registration nursing curriculum. Consequently the NMC currently permit 300 hours, from the allocation of 2,300 direct care hours $(6 \%$ of the overall total of theory and practice hours), for the use of simulated practice learning. The remit of the allowance is the CSL environment must support the development of direct care skills, as stated within the Standards for Pre-registration Education (NMC 2010). In May 2018 in the UK, the NMC published new standards for pre-registration nurse education due to be introduced in January 2019 (NMC 2018). Within these changes it is stated that simulation activities may be further increased, which may fundamentally alter the role of SBE within nurse education such there is a potential that it will 
have an even greater impact on students' clinical learning outcomes.

Consequently time in the clinical learning environment (CLE) may be reduced for students in favour of SBE, such that discussion about where theory and practice sit within the curriculum needs further exploration.

There have been many perceptions about the value and purpose of simulation learning. Cant and Cooper (2010), discussed in their systematic review, that:

'Simulation enables nurses to develop, synthesize and apply their knowledge in a replica of real experience' (p.13)

The value of a CSL, being a safe environment in which to learn, is two-fold. Firstly, Linder and Pulsipher (2008) assert it allows students the opportunity to engage in skills learning in a controlled and supervised environment, which closely represents reality. Secondly, it aids students with understanding and reacting to patient care needs without exposing real patients to harm or risk (Robinson \& Dearmon, 2013). Both of these factors are essential for the skilled, up-to-date nursing workforce, so it is encouraging that Hope et al (2011) declare that the provision of the CSL as a learning environment for students has been positively evaluated within the literature. Learning in a CSL, students can test their critical thinking skills, rehearse decision-making and react to unpredictable health events in any given scenario using HPS, in a 'safe' situation supported by lecturing staff. In order for the SBE to be effective it must reflect reality using a high fidelity approach (Maran and Glavin 2003), such that the 'reality shock' of applying nursing skills in the clinical placement environment will be minimised. However, McCaughey and Traynor (2010) and Brown and Chronister (2009) recommend caution is applied with the assumption that learning has occurred when simulation has featured within the curriculum is erroneous; indeed questions have been raised regarding the transferability of simulation learning to practice (Gordon et al 2013, Murray et al 2008). 


\section{$\underline{\text { Consequences }}$}

Rodgers (2000) describes consequences as outcomes, portraying what happens after an incidence of the concept occurs. These were found to be: Influence on nurses and nursing students, and disparity in collaboration between clinical staff and academics.

\section{Influence on nurses and nursing students}

The theory-practice gap is highlighted by factors including barriers to skill acquisition, the need for increased practice time in a CSL and the issue of socialisation to the environment (Sharif and Masoumi 2005). Students exhibit a need to 'fit in' and Ousey and Gallagher (2007) discuss how, in order to become an accepted member of the team and part of the culture, students will often emulate their peers. Effective role models are needed to facilitate positive professional socialisation, which Aled (2007) has dubbed as the 'hidden curriculum' in nursing; whereas the new term of the 'para-curriculum' is suggested by Allan et al (2011). Both Scully (2011) and Allan et al (2011) argue clinically competent mentors, who provide support and guided time to reflect and debrief with students, are instrumental for successful student socialisation. It is acknowledged by Scully (2011) and Maben et al (2006) mentors with good relationship with their students are highly valued, as they integrate technical proficiency whilst also challenging the student on their theoretical and contextual knowledge.

A response to attempts to conform with a mentor's practice, or with the provision of care in a clinical area, may result in experiencing moral distress (Rushton 2006) or cognitive dissonance (Festinger 1957). Dissonance can occur when nurses are faced with new or existing knowledge that conflicts with their own beliefs or values. Hence students may find themselves in a situation where the skills teaching at university advocates a certain way of performing a skill, yet mentors feel unable or unwilling to assess them using these methods, resulting in cognitive dissonance caused by the stress of 
negotiating a theory-practice gap. The dissonance or distress felt may cause stress, anxiety or feelings of incompetence.

\section{Disparity in collaboration between clinical staff and academics.}

Scully (2011) suggests the creation of a collaborative relationship between academic and clinical staff is of the utmost importance when developing education strategies. Haigh (2008) concurs, proposing academics should work with and support clinically credible colleagues to produce a curriculum which spans both the theoretical and practice domains, whilst also engaging in jointly managed research projects to enhance the professional profiles of both sides of the theory-practice gap.

By contrast, Ousey and Gallagher (2007) suggest that the division of power between nursing academics and practitioners is unequal, with academics traditionally enjoying more powerful positions, as 'knowing' has been seen as more valuable than 'doing'. This may have some veracity, as academics (whilst not assessing the student in practice) do retain responsibility and influence via curriculum design, educational audits and management of the assessment portfolios or documents. This unbalanced relationship needs to be redressed for a successful collaborative affiliation to succeed. Such collaboration will ultimately lead to greater coherence in nurse education, where students will perceive a connection between studying theory and practical nursing. Hatlevik (2011) advocates this balanced collaboration will result in the ability to build practice upon theoretical knowledge in addition to practical experience, providing better understanding of the theoretical underpinning of educational knowledge.

\section{$\underline{\text { Model case }}$}

Rodgers' model (2000) includes a description of a real-life case or situation of the phenomenon occurring, to be presented as an exemplar of the concept. In this case Cornish and Jones' (2007) mixed method study of 106 student nurses regarding moving and handling training is used. This study used a 
survey, unstructured follow-up interviews, and subsequently focus groups from a different cohort of students for triangulation purposes. In the study the students' responses were categorised into two key areas: poor practice and constraints on practice. The poor practice ranged from inappropriate techniques and poor posture through to using incorrect equipment, or no equipment, even when it was available. Seventy one percent of students reported being asked to participate in a manoeuvre they knew to be wrong, while $74 \%$ had been asked to lift the body weight of a patient, which directly contravenes the Trusts' 'no lift' policy. The constraints on practice were noted as a lack of appropriate equipment, lack of staff or time, or incorrectly perceiving a situation as an emergency (Cornish and Jones 2007 p 132). The reasons for the students engaging with unsafe manual handling ranged from the practical, such as a lack of available equipment or adequate space, through to socialisation issues, including poor role models within the ward staff and feeling powerless to question practices for fear of being ridiculed. This case identifies and describes a theory-practice gap, where evidence regarding handling techniques is being ignored and the activities students engage in or observe directly contravene the techniques taught in university. Other nursing skills could have been chosen to represent this model case, and indeed within the subsequent doctoral study IMIs were selected as the exemplar skill with which to examine student nurses' experiences of a theorypractice gap.

\section{Summary}

The metaphor of a theory-practice gap is habitually used, yet its definition remains unclear and has, as Gallagher (2004) asserts, become a 'useful and convenient shorthand' for a complex educational problem ( $p$ 44). The concept analysis reported here has sought to provide clarity to a virtual gap; one that is felt, frequently discussed, yet about which there is no consensus regarding its foundations, characteristics or consequences. There is still worldwide unease and discomfort about the existence of a theory-practice gap and its consequential effects, such as moral distress and cognitive dissonance. The consequences of whether or not students recognise the theory-practice gap, 
and of the strategies they adopt to negotiate and manage their responses to it, are of particular interest for future study and indeed were investigated as part of a doctoral research programme case study. Performing this concept analysis also allowed for the creation of a new contemporary definition of the term theory-practice gap, which was therefore used as a basis for the subsequent doctoral research programme, using IMI as a case study exemplar.

\section{References}

Aled, J. (2007). Putting practice into teaching: an exploratory study of nursing undergraduates' interpersonal skills and the effects of using empirical data as a teaching and learning resource. Journal of Clinical Nursing, 16, 2297-2307. https://doi.org/10.1111/j.1365-2702.2007.01948.x

Allan, H., Smith, P., O'Driscoll, M. (2011). Experiences of supernumerary status and the hidden curriculum in nursing: a new twist in the theory-practice gap? Journal of Clinical Nursing, 20, 847-855. https://doi.org/10.1111/j.1365-2702.2010.03570.x

Allen, J. (2009). Valuing practice over theory: How beginning teachers re-orient their practice in the transition from university to the workplace. Teaching and Teacher Education, 25, 647-654. https://doi.org/10.1016/j.tate.2008.11.011

Allmark, P. (1995). A classical view of the theory-practice gap in nursing. Journal of Advanced Nursing, 22, 18-23. https://doi.org/10.1046/j.1365-2648.1995.22010018.x

Aveyard, H., Sharp, P (2017) A beginner's guide to evidence based practice. $3^{\text {rd }}$ Edn. Maidenhead: Open University Press.

Barrett, D. (2006). Clinical role of nurse lecturers: past, present and future. Nurse Education Today, 27, 367-374. https://doi.org/10.1016/j.nedt.2006.05.018

Brown, D., Chronister, C. (2009). The effect of simulation on critical thinking and self confidence when incorporated into an electrocardiogram nursing course. Clinical Simulation in Nursing, 5(1), e45-e52. https://doi.org/10.1016/j.ecns.2008.11.001

Cant, R. P., Cooper, S. (2010). Simulation-based learning in nurse education: systematic review. Journal of Advanced Learning, 66 (1), 3-15. https://doi.org/10.1111/j.1365-2648.2009.05240.x 
Cheng, M., Cheng, A., Tang, S. (2010). Closing the gap between the theory and practice of teaching: implications for teacher education programmes in Hong Kong. Journal of Education for Teaching, 36(1), 91-104. https://doi.org/10.1080/02607470903462222

Cornish, J., Jones, A. (2007). Evaluation of moving and handling training for preregistration nurses and its application to practice. Nurse Education in Practice,7,128134. https://doi.org/10.1016/j.nepr.2006.04.010

Darbyshire, P. (2010). Joint or clinical chairs in nursing: from cup of plenty to poisoned chalice. Journal of Advanced Nursing, 66(11), 2592-2599.

https://doi.org/10.1111/j.1365-2648.2010.05452.x

Duncan, C., Cloutier, J. D., Bailey, P. H. (2007). Concept analysis: the importance of differentiating the ontological focus. Journal of Advanced Nursing, 58(3), 293-300. https://doi.org/10.1111/j.1365-2648.2007.04277.x

Evans, M. (2009). Tackling the theory-practice gap in mental health nurse training. Mental Health Practice, 13(2), 21-24.

Festinger, L (1957) A Theory of Cognitive Dissonance. London: Tavistock

Gallagher, P. (2004). How the metaphor of a gap between theory and practice has influenced nursing education. Nurse Education Today, 24(4), 263-268.

https://doi.org/10.1016/j.nedt.2004.01.006

Glenn, G. (2006). New perspectives on old debates: re-engineering the theorypractice gap. Australian Journal of Advanced Nursing, 24(2), 7-8.

Gordon, C. J., Frotjold, A., Fethney, J., Green, J., Hardy, J., Maw, M., Buckley, T. (2013). The effectiveness of simulation-based blood pressure training in preregistration nursing students. Simulation Healthcare, 8(5), 335-340. doi: 10.1097/SIH.0b013e3182a15fa7

Haigh, C. (2008). Embracing the theory-practice gap. Journal of Clinical Nursing, 18, 1-2. https://doi.org/10.1111/j.1365-2702.2008.02325.x

Hancock, H., Lloyd, H., Campbell, S., Turlock, C., Craig, S. (2007). Exploring the challenges and successes of the Lecturer Practitioner role using a stakeholder evaluation approach. Journal of Evaluation in Clinical Practice, 13, 758-764. https://doi.org/10.1111/j.1365-2753.2006.00750.x

Hatlevik, I. (2011). The theory-practice relationship: reflective skills and theoretical knowledge as key factors in bridging the gap between theory and practice in initial nursing education. Journal of Advanced Nursing, 68(4), 868877. https://doi.org/10.1111/j.1365-2648.2011.05789.x

Hope, A., Garside, J., Prescott, S (2011) Rethinking theory and practice: Preregistration student nurses experiences of simulation teaching and learning in the 
acquisition of clinical skills in preparation for practice. Nurse Education Today 31, 711-715. https://doi.org/10.1016/j.nedt.2010.12.011

Korthagen, F., Loughran, J., Russell, T. (2006). Developing fundamental principles for teacher education programs and practices. Teaching and Teacher Education, 22(8), 1020-1041. https://doi.org/10.1016/j.tate.2006.04.022

Linder, L. A., Pulsipher, N. (2008). Implementation of simulated learning experiences for baccalaureate paediatric nursing students. Clinical Simulation Nursing, 4(3), e41-e47. https://doi.org/10.1016/j.ecns.2008.09.002

Maben, J., Latter, S., Macleod Clark, J. (2006). The theory-practice gap: impact of professional-bureaucratic work conflict on newly qualified nurses. Journal of Advanced Nursing, 55(4), 465-477. https://doi.org/10.1111/j.13652648.2006.03939.x

Maran, N., Glavin, R. (2003). Low-to-high-fidelity simulation - a continuum of medical education? Medical Education, 37(1), 22-28. https://doi.org/10.1046/j.13652923.37.s1.9.x

McCaughey, C. S., Traynor, M. K. (2010). The role of simulation in nurse education. Nurse Education Today, 30(8), 827-832. https://doi.org/10.1016/j.nedt.2010.03.005

Monaghan, T. (2015). A critical analysis of the literature theoretical perspectives on the theory-practice gap amongst qualified nurses within the United Kingdom. Nurse Education Today, 35(8), e1-e7. https://doi.org/10.1016/j.nedt.2015.03.006

Murray, C., Grant, M. J., Howarth, M. L., Leigh, J. (2008). The use of simulation as a teaching and learning approach to support practice learning. Nurse Education in Practice, 8, 5-8. https://doi.org/10.1016/j.nepr.2007.08.001

Myall, M., Levett-Jones, T., Lathlean, J. (2008). Mentorship in contemporary practice: the experience of nursing students and practice mentors. Journal of Clinical Nursing, 17(14), 1834-1842. https://doi.org/10.1111/j.1365-2702.2007.02233.x

Nursing and Midwifery Council (2007) Supporting Direct Care through Simulated Practice Learning in the Pre-Registration Nursing Programme (NMC Circular Ed.). London: NMC.

Nursing and Midwifery Council (2010) Standards for Pre-Registration Nursing Education. London: NMC.

Nursing and Midwifery Council (2018) Standards for Pre-Registration Nursing Programmes. London: NMC.

Nursing and Midwifery Council. (2015). The Code: Standards of Conduct, Performance and Ethics for Nurses and Midwives. Retrieved from http://www.nmc.org.uk/standards/code/ accessed on 12/3/18

Ousey, K., Gallagher, P. (2007). The theory-practice relationship in nursing: A 
debate. Nurse Education in Practice, 7, 199-205.

https://doi.org/10.1016/j.nepr.2007.02.001

Ousey, K., Gallagher, P. (2010). The clinical credibility of nurse educators: Time the debate was put to rest. Nurse Education Today, 30, 662-665.

https://doi.org/10.1016/j.nedt.2009.12.021

Risjord, M. (2009). Rethinking concept analysis. Journal of Advanced Nursing, 65(3), 684-691. https://doi.org/10.1111/j.1365-2648.2008.04903.x

Robinson, B. K., Dearmon, V. (2013). Evidence-based nursing education: effective use of instructional design and simulated learning environments to enhance knowledge transfer in undergraduate nursing students. Journal of Professional Nursing, 29(4), 203-209. https://doi.org/10.1016/j.profnurs.2012.04.022

Rodgers, B. (2000). Concept analysis: an evolutionary view. In B. Rodgers \& K. Knafl (Eds.), Development in Nursing- Foundations, Techniques and Applications (2nd ed., pp. 77-100). Philadelphia: W B Saunders.

Rolfe, G. (1998). The theory-practice gap in nursing: from research-based practice to practitioner based research. Journal of Advanced Nursing, 28(3), 672-679 https://doi.org/10.1046/j.1365-2648.1998.00806.x

Rolfe, G. (2002). Closing the theory-practice gap. Edinburgh: Elsevier Science Limited.

Rushton, C (2006) 'Defining and addressing moral distress: tools for critical care nursing leaders', AACN Advanced Critical Care, 17(2), pp.161-8.

Sanfilippo, A. (2016). Bridging the gap between theory and practice in medical education: Entrusbable professional activities. Undergraduate school of medicine blog, 22 June, available at: https://meds.queensu.ca/blog/undergraduate/?p=2219. (Accessed 21/10/17)

Scovell, S. (2010). Role of the Nurse-to-Nurse Handover in Patient Care. Nursing Standard, 24(20), 35-39.

Scully, N. J. (2010). The theory-practice gap and skill acquisition: An issue for nursing education. Collegian, 18, 93-98. https://doi.org/10.1016/j.colegn.2010.04.002

Sharif, F., Masoumi, S. (2005). A qualitative study of nursing student experiences of clinical practice. BioMed Central Nursing, 4(6). https://doi.org/10.1186/1472-6955-46

Smeby, J.-C., Vagan, A. (2008). Recontextualising professional knowledge- newly qualified nurses and physicians. Journal of Education and Work, 21(2), 159-173. https://doi.org/10.1080/13639080802018014

Tofthagen, R., \& Fagerstrøm, L. (2010). Rodgers' evolutionary concept analysis- A valid method for developing knowledge in nursing science. Scandinavian Journal of 
Caring Sciences, 24, 21-31. https://doi.org/10.1111/j.1471-6712.2010.00845.x

Voldbjerg, S. L., Gronkjaer, M., Sorensen, E. E., Hall, E. O. C. (2016). Newly graduated nurses' use of knowledge sources: a meta-ethnography. Journal of Advanced Nursing, 72(8),pp.1751-1765. https://doi.org/10.1016/j.nedt.2018.02.008

Walker, L. O., Avant, K. C. (2005). Strategies for Theory Construction in Nursing (4th ed.) Upper Saddle River, NJ: Pearson Prentice Hall.

Wilson, J. (1963). Thinking with Concepts. Cambridge: Cambridge University Press. 